\title{
New treatment at source approach using combination of microfiltration and nanofiltration for dyeing effluents reuse
}

\author{
G. Masmoudi • R. Trabelsi • E. Ellouze • \\ R. B. Amar
}

Received: 10 August 2012/Revised: 25 March 2013/Accepted: 23 April 2013/Published online: 17 May 2013

(C) Islamic Azad University (IAU) 2013

\begin{abstract}
Textile effluents are considered among the most polluted wastewaters all over the world. Among different textile processes, dyeing is the operation that produces the most important amounts of chemical pollution. Many studies have been carried out toward the treatment of these hazardous effluents, and a variety of techniques have been applied for this aim. In this work, the effluents coming from different steps of the dyeing cycle were treated following different mixtures of baths using membrane technology. Nanofiltration (NF) experiments were performed for color removal, but membrane fouling still a major limitation. To enhance NF performances, microfiltration (MF) was carried out as pretreatment to NF. The results showed almost above $99 \%$ of color and turbidity removal and also an important decrease in COD, chloride and salts contents with an improvement in the MF and NF stabilized fluxes of different mixtures compared to that corresponding to the dyeing effluent treated separately. In order to accomplish a full reuse cycle, dyeing experiments were performed using the combined system (MF/NF) permeates. Results were evaluated regarding total color difference between samples and a standard test done with fresh water.
\end{abstract}

Keywords Baths mixtures - Dyeing cycle . Microfiltration · Nanofiltration · Reuse

G. Masmoudi · R. Trabelsi · E. Ellouze · R. B. Amar $(\bowtie)$ Laboratory of Material Sciences and Environment, Faculty of Sciences of Sfax, Soukra road km 4, 3000 Sfax, Tunisia e-mail: Raja.rekik@fss.rnu.tn

\section{Introduction}

In order to achieve a finished product, the textile item has to undergo through different processing stages, but dyeing remains the most important. Industrial dyeing process includes several operations such as pretreatment, dyeing, washing, neutralizing and softening. Some operations are followed by one or more rinsing step. Therefore, large amounts of water have to be used to achieve the dyeing cycle. Allègre et al. (2006) noticed that $1 \mathrm{~kg}$ of cotton requires an average of 70-150 1 of fresh water.

Reactive dyes are widely used for dyeing cellulose as well as cotton fibers. However, in this case, the dyeing process requires large amounts of salts and dyes to achieve a good product quality: $1 \mathrm{~kg}$ of cotton requires $0.6 \mathrm{~kg}$ of $\mathrm{NaCl}$ and $40 \mathrm{~g}$ of reactive dye (Allègre et al. 2006).

Direct discharge of the generated effluents into the environment can cause irreversible ecological problems such as eutrophication and anarchic algae proliferation in the aquatic systems (Khataee et al. 2010) and can have disastrous effects on potable water even in the deepest aquifers. So, there is a stringent need to suitably treat the dyeing effluents before discharge.

Membrane treatment is relatively a recent technology, but it is shown to be efficient for the treatment of the dyeing effluents (Uzal et al. 2009; Katarzyna 2010). Textile wastewater reuse is strongly related with membrane processes, especially nanofiltration (NF) process which has been widely studied (Tang and Chen 2002; Wenzel et al. 1996; Zahrim et al. 2011). Because of the reduced pore size of NF membrane (almost $10^{-9} \mathrm{~m}$ ) against the important pollutant charge of the dyeing effluent, membrane fouling represents the major limitation for the use of single NF treatment. Fouling is susceptible to damage the membrane and reduce its life time also it leads to high operational 
costs. To prevent fouling effects on the membrane and to enhance NF performances, a pretreatment was necessary. Two treatment methods can generally be used, either hybrid treatment or membrane processes combination.

For hybrid treatment, NF can be coupled with traditional biological treatment with activated sludge (Sahinkaya et al. 2008; Suksaroj et al. 2005). Fersi et al. (2005) found that the use of NF after biological treatment gives more than $90 \%$ of removal of color, turbidity and TDS. Coagulation/ flocculation $(\mathrm{C} / \mathrm{F})$ can be also used prior to Rierra-Torres et al. (2010) found that the combination of $\mathrm{C} / \mathrm{F}$ and $\mathrm{NF}$ almost provided more than $90 \%$ of color retention for different dyes solutions. Zahrim et al. (2011) studied the potential of coagulation flocculation to minimize the fouling of NF membrane during the treatment of highly concentrated dyes solutions. Electro-coagulation is also a new technology for the treatment of textile effluents which can be combined with NF for wastewater reuse; Aouni et al. (2009) observed that following this approach, a color removal of more than $99 \%$ was mostly obtained. All these methods give acceptable results when coupled with NF, but there is an urgent need to develop more efficient and inexpensive methods which can be automatically monitored and require fewer chemicals and energy consumptions and less installation spaces.

The combination of membranes processes meets the economical requirement as well as space constraints and improves the treated water quality when compared with conventional methods. Ellouze and Tahri (2012) found that the use of microfiltration (MF) as pretreatment for NF when compared with $\mathrm{C} / \mathrm{F}$ altered the treatment performances in pollutants removal regarding color $(96.2 \%$ with $\mathrm{MF}$ and $92.8 \%$ with $\mathrm{C} / \mathrm{F}$ ) and salt removal (26\% with MF against $15.7 \%$ with C/F). Rozzi et al. (1999) found that COD and color removal were almost 70 and $95 \%$, respectively, in most cases when MF is coupled with NF as a pretreatment. Unlu et al. (2009) tested different combinations of coagulation, MF, UF and NF and found that MF/ NF system was found to be the optimum treatment scheme in the treatment of indigo dyeing wastewater.

The treatment at source of textile effluent seems to be a good alternative to reduce the overall flow and the complexity of the effluent, especially for the treatment of the dyeing bath producing small volumes of water compared with other operations, but with substantial pollution concentrations. In this treatment configuration, the dye bath wastewater can be isolated and treated separately, but with this highly concentrated effluent, fouling problems may occur when using a single membrane processes treatment. To avoid fouling problems, a $\mathrm{C} / \mathrm{F}$ as well as sand filtration can be applied as pretreatment (Rierra-Torres et al. 2010; Ranganathan et al. 2007). On the other hand, dyeing bath wastewater can be mixed with the other effluents coming from the dyeing process in order to be diluted and in an attempt to have favorable reactions between different baths components (Wenzel et al. 1996). In this context, surfactants substances, widely used in the dyeing process, should be taken into account. The relation between the use of surfactant and the enhancement of dye removal from textile wastewater has been reported by many studies. Kartal and Akbas (2005) investigated the possible interactions between anionic or nonionic surfactant with anionic reactive dye and found that while nonionic surfactant form a complex with the dye molecule, the anionic one does not, also the use of two surfactants simultaneously increased the absorbance value. In the same context, Akbas and Kartal (2005) studied the interactions between cationic or nonionic surfactant and anionic reactive dye; they found that the stability of the complex cationic surfactant-anionic dye was reduced when a nonionic surfactant was added. Zaghbani et al. (2008) found that the use of anionic surfactants with cationic dyes enhanced color rejection by UF membrane providing color removal more than $97 \%$.

In this work, the investigation was carried out during the period from January to July 2012 in a textile manufactory located in ksar Hellal, Tunisia. The effluents used in this study were real dye house wastewaters. Pilot scale separation system based on coupled MF and NF was used in the treatment of mixtures of different baths released from the operations of the dyeing cycle. The objective of this study was to evaluate the MF/NF performances in the treatment at source of concentrated dyeing effluents and to check the reusability of the treated water in the dyeing process.

\section{Materials and methods}

\section{Dyeing cycle and baths mixing}

The effluents were generated from industrial dyeing process of cotton with reactive dyes. Table 1 regroups the various steps of the studied industrial process of reactive dyeing, the conditions of application and the type of auxiliaries added in each operation. The volume of water used in the process depends on the material weight; $1 \mathrm{~kg}$ of cotton requires about 101 of fresh water in each step, therefore the same volume of water is used in each operation.

The molecule of reactive dye is composed of a chromophore group and reactive chemical group forming covalent bond with the fiber. The reactive chemical linker called "Dichlorotriazin" is negatively charged and acts as a connecting agent between the dye and the substrate (Donzé 1988). In our case, three reactive dyes were used simultaneously in the dyeing bath: yellow, red and blue (Table 2). 
The followed treatment scheme consisted on the isolation of the dyeing bath releasing the most polluted effluent in order to treat it separately in a first step. To dilute this concentrated effluent, a mixture of all the effluents coming from the different operations of the dyeing cycle was considered (end of pipe effluent). Finally, a new approach consisting in mixing the dyeing bath with the other baths one by one and then with two baths by making all possible combinations was followed.

\section{Membranes}

In the coupled treatment, MF was used prior to NF. The MF permeate was fed to the NF membrane. The MF and NF concentrates were fed back into the MF and NF membranes, respectively. NF permeate was recovered for reuse dyeing tests (Fig. 1).

\section{MF membrane}

Membralox module (1P19-40/1R19-40) of 1,020 mm length was used in the experiments. The membrane is a multi-channel type (19 channels) made of porous ceramic based on alumina with an area of $0.24 \mathrm{~m}^{2}$ and pore size of $0.2 \mu \mathrm{m}$.

All MF experiments were performed under 2 bar pressure and $50{ }^{\circ} \mathrm{C}$ which is almost the temperature of the effluents at the outlet of the dyeing machine.

For the evaluation of MF rejection, the percent reduction of each parameter (COD, turbidity and color) was determined from the concentration of the parameter in the feed and the MF permeate ( $C_{\mathrm{f}}$ and $C_{\mathrm{p} . \mathrm{MF}}$, respectively) as follows:

$R(\%)=\left(1-\frac{C_{\mathrm{p} . \mathrm{MF}}}{C_{\mathrm{f}}}\right) \times 100$
Table 2 Reactive dyes used in the process

\begin{tabular}{lll}
\hline Type & Formula & Concentration $(\mathrm{g} / \mathrm{l})$ \\
\hline Reactive yellow 145 & $\mathrm{C}_{28} \mathrm{H}_{20} \mathrm{Cl} \mathrm{N}_{9} \mathrm{O}_{16} \mathrm{~S}_{5} \mathrm{Na}_{4}$ & 1.33 \\
Reactive red 120 & $\mathrm{C}_{44} \mathrm{H}_{24} \mathrm{Cl}_{2} \mathrm{~N}_{14} \mathrm{O}_{20} \mathrm{~S}_{6} \mathrm{Na}_{6}$ & 3.68 \\
Reactive blue 222 & $\mathrm{C}_{37} \mathrm{H}_{23} \mathrm{Cl} \mathrm{N}_{10} \mathrm{O}_{22} \mathrm{~S}_{7} \mathrm{Na}_{6}$ & 1.24 \\
\hline
\end{tabular}

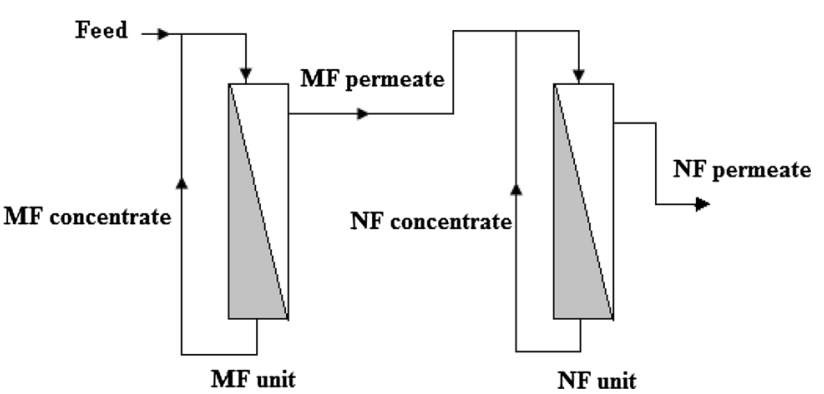

Fig. 1 Schematic presentation of the experimental setup of MF/NF combination

\section{NF membrane}

For NF experiments, a spiral DESAL membrane product (DK2540F1073) having a MWCO of $200 \mathrm{Da}$, a length of $1,016 \mathrm{~mm}$ and an area of $2.5 \mathrm{~m}^{2}$ was used.

The temperature of the effluent in the outlet of MF was close to $40{ }^{\circ} \mathrm{C}$, which was chosen as the operating temperature of NF membrane. The operational pressure was fixed after a series of experiments detailed in a previous work (Tahri et al. 2012); 12 bar was considered the optimal TMP value for all the NF runs in this work.

The efficiency of different parameters removal after the $\mathrm{NF}$ treatment was calculated from the concentrations in the MF and NF permeates ( $C_{\mathrm{p} . \mathrm{MF}}$ and $C_{\mathrm{p} . \mathrm{NF}}$, respectively) using the rejection parameter as follows:

Table 1 Operating conditions of the dyeing process steps

\begin{tabular}{|c|c|c|c|c|c|}
\hline Operation & $\mathrm{pH}$ & $T\left({ }^{\circ} \mathrm{C}\right)$ & $t(\min )$ & Additives & Role \\
\hline Preparation $(\mathrm{P})$ & $6-7$ & 30 & 5 & $\begin{array}{l}\text { Sequestering agent (anionic surfactant) } \\
\text { Corrosion protector agent (anionic) } \\
\text { Acetic acid }\end{array}$ & $\begin{array}{l}\text { Attach hardening substances } \\
\text { Prevent corrosion of metallic buttons, } \\
\text { fasteners and zipper }\end{array}$ \\
\hline Dyeing (D) & $9-11$ & 60 & 110 & $\begin{array}{l}\text { Reactive dyes (anionic) } \\
\text { Salt (sodium chloride) } \\
\text { Sodium carbonate } \\
\text { Sodium hydroxide }\end{array}$ & $\begin{array}{l}\text { Operation of attaching the dye molecule } \\
\text { to the textile }\end{array}$ \\
\hline Neutralizing $(\mathrm{N})$ & $6-7$ & 50 & 5 & Acetic acid & Add of acid to adjust the basic $\mathrm{pH}$ of the tissue \\
\hline Washing (W) & $6-7$ & 80 & 5 & $\begin{array}{l}\text { Dispersing and degreasing detergent } \\
\text { (nonionic surfactant) }\end{array}$ & $\begin{array}{l}\text { Eliminate the excess of dyes and auxiliaries } \\
\text { not fixed on the fiber }\end{array}$ \\
\hline Softening (S) & $5-6$ & 40 & 20 & $\begin{array}{l}\text { Acetic acid } \\
\text { Softening agent (cationic surfactant) }\end{array}$ & Enhance the feel of textile \\
\hline
\end{tabular}


$R(\%)=\left(1-\frac{C_{\mathrm{p} . \mathrm{NF}}}{C_{\mathrm{p} . \mathrm{MF}}}\right) \times 100$

Dye mass balance

To understand the behavior of the MF membrane toward dye molecules and to study the fouling phenomenon established on the membrane surface, a color mass balance was established for each configuration. The mass percentage of color in the permeate, in the concentrate and adsorbed by the membrane, respectively, $X_{\mathrm{p}}, X_{\mathrm{c}}$ and $X_{\varepsilon}$, was calculated as follows:

$X_{\mathrm{p}}(\%)=\frac{m_{\mathrm{p}}}{m_{\mathrm{f}}} \times 100$

$X_{\mathrm{c}}(\%)=\frac{m_{\mathrm{c}}}{m_{\mathrm{f}}} \times 100$

$X_{\varepsilon}(\%)=\frac{m_{\mathrm{f}}-m_{\mathrm{p}}-m_{\mathrm{c}}}{m_{\mathrm{f}}} \times 100$

$m_{\mathrm{f}}, m_{\mathrm{p}}$ and $m_{\mathrm{c}}$ are, respectively, the amount of dye in the feed, in the permeate and in the concentrate and are calculated from the dye concentrations $C_{\mathrm{f}}, C_{\mathrm{p}}$ and $C_{\mathrm{c}}$ and the total volumes of the feed, the permeate and the concentrate which are, respectively, 60, 45 and 151 . The concentration of dye was calculated from the Beer Lambert law connecting linearly the absorbance value to the concentration.

\section{Analytical methods}

The dye amounts were followed by absorbance measurements at the visible maximum dye absorption wavelength using a UV-visible spectrophotometer (Perkin Elmer Lambda 20 UV/VIS).

COD was estimated by open reflux method. The protocol present a method derived from the standard AFNOR T90-101. The COD values were obtained using a Fisher Bioblock Scientific reactor COD 10119 type COD-meter.

Turbidity was measured using a turbidity-meter Hach RATIO 2,100 N. Chloride amounts were calculated after a simple dosage by $\mathrm{AgNO}_{3}$, salinity was measured with a conductimeter Tascussel model 123 and total hardness was calculated using a complexometric titration with EDTA.

\section{Textile color measurement}

Color can be represented by a point in a space formed by three orthogonal axes: the first describes color evolution from green $\left(-a^{*}\right)$ to red $\left(+a^{*}\right)$, the second identifies color evolution from blue $\left(-b^{*}\right)$ to yellow $\left(+b^{*}\right)$ and the third one represents lightness $L^{*}$ ranging from 0 for black to 100 for perfect white. In this measurement method, a comparison against a color standard is required. So, total color differences $\Delta E$ can be calculated from analysis of samples and standard, following Eq. 6.

$$
\begin{aligned}
& \Delta E=\sqrt{\left(\Delta a^{*}\right)^{2}+\left(\Delta b^{*}\right)^{2}+\left(\Delta L^{*}\right)^{2}} \\
& \Delta a^{*}=a_{\text {sample }}^{*}-a_{\text {standard }}^{*}, \Delta b^{*}=b_{\text {sample }}^{*}-b_{\text {standard }}^{*} \\
& \Delta L^{*}=L_{\text {sample }}^{*}-L_{\text {standard }}^{*}
\end{aligned}
$$

The spectrocolorimeter used is Datacolor Spectrum 2520. Samples are textile items dyed with NF permeates. Standard reference is a textile dyed with fresh water using the same dyeing protocol. The samples giving the best results should have a total color difference $\Delta E$ close to zero. Then, the similarity between standard and samples was calculated following:

similarity $(\%)=(1-\Delta E) \times 100$

\section{Results and discussion}

\section{Effluents characterization}

Before studying the performances of the treatment, it was necessary to identify the pollution level of the effluents to be treated (Table 3). Noting that the released effluents from various steps of the dyeing cycle have the same volume, the dyeing bath shows the most complex composition due to the presence of hydrolyzed reactive dyes, salt, sodium carbonate, sodium hydroxide and residual compounds. The end of pipe effluent, in which the dyeing bath is maximally diluted, represents the lowest color and turbidity values.

\section{MF step}

\section{Quantitative performances}

First of all, from Table 3, it has to be noticed that the $\mathrm{pH}$ values of the treated effluents were above the isoelectric point (IEP) of the MF membrane which is between 6 and 7.5 (Katarzyna 2010). Thus, it can be concluded that the MF membrane will be charged negatively during the filtration process. The performances of $\mathrm{MF}$ membrane regarding the permeate flux were presented in Fig. 2.

During filtration runs, important flux decline was obvious for most combinations especially in the first $10 \mathrm{mn}$, the permeate flux reach a steady value when the fouling layer development completed (Uzal et al. 2006). It seems that the lowest performances regarding permeate flux were obtained with the end of pipe and the dyeing effluents. The membrane fouling appears more severe with the end of pipe effluent since an important flux decline was observed 
Table 3 Characterization of different baths combinations

\begin{tabular}{|c|c|c|c|c|c|c|c|c|}
\hline Configuration & $\mathrm{pH}$ & TDS $(\mathrm{g} / \mathrm{l})$ & $S(\mathrm{~g} / \mathrm{l})$ & $\mathrm{TH}\left({ }^{\circ} \mathrm{F}\right)$ & $\mathrm{Cl}^{-}(\mathrm{g} / \mathrm{l})$ & $\operatorname{COD}(\mathrm{g} / \mathrm{l})$ & Color $^{\mathrm{a}}$ & Turb (NTU) \\
\hline $\mathrm{D}$ & 11.49 & 111.8 & 107.2 & 220 & 44.37 & 3.2 & 7.6 & 16.2 \\
\hline End of pipe & 9.53 & 20.4 & 19.1 & 140 & 12.55 & 1.7 & 3.7 & 7.5 \\
\hline $\mathrm{D}+\mathrm{P}$ & 10.37 & 23.4 & 21.3 & 120 & 14.2 & 1.7 & 4.5 & 9.7 \\
\hline $\mathrm{D}+\mathrm{W}$ & 11.25 & 38.1 & 36.4 & 260 & 19.88 & 1.5 & 4.6 & 11.9 \\
\hline $\mathrm{D}+\mathrm{N}$ & 10.04 & 37.9 & 36.3 & 240 & 23.43 & 1.6 & 5.3 & 11.1 \\
\hline $\mathrm{D}+\mathrm{S}$ & 10.58 & 35.2 & 34.4 & 172 & 18.85 & 2.3 & 5.1 & 9.5 \\
\hline $\mathrm{D}+\mathrm{W}+\mathrm{P}$ & 9.71 & 21.93 & 20.1 & 208 & 9.23 & 1.2 & 3.4 & 9.79 \\
\hline $\mathrm{D}+\mathrm{W}+\mathrm{N}$ & 10.71 & 20.59 & 18.3 & 103 & 9.56 & 1.4 & 3.6 & 10.5 \\
\hline $\mathrm{D}+\mathrm{W}+\mathrm{S}$ & 9.93 & 23.1 & 22.9 & 180 & 12.78 & 2.6 & 4.4 & 8.4 \\
\hline $\mathrm{D}+\mathrm{P}+\mathrm{S}$ & 10.03 & 18.13 & 17.7 & 251 & 10.65 & 1.7 & 4.1 & 9.7 \\
\hline $\mathrm{D}+\mathrm{N}+\mathrm{S}$ & 11.35 & 22.1 & 20.9 & 248 & 10.65 & 2.8 & 5.4 & 7.64 \\
\hline $\mathrm{D}+\mathrm{N}+\mathrm{P}$ & 8.9 & 23.89 & 20.5 & 168 & 14.2 & 1.8 & 5.7 & 10.2 \\
\hline
\end{tabular}

${ }^{\text {a }}$ Integral of the absorbance curve in the hole visible range (400-800 nm)

during the first $20 \mathrm{~min}$ of filtration, after that the flux decreases slightly to stabilize at $401 / \mathrm{h} \mathrm{m}^{2}$ with $70 \%$ of flux decline against only $22 \%$ for the dyeing effluent with a stabilized flux of $60 \mathrm{l} / \mathrm{h} \mathrm{m}^{2}$.

The approach considering the treatment at source following a specific mixture of different baths seems giving better filtration results especially with $\mathrm{D}+\mathrm{W}+\mathrm{N}$ and $\mathrm{D}+\mathrm{W}+\mathrm{P}$ configurations reaching a stabilized permeate flux, respectively, of 143 and $139 \mathrm{l} / \mathrm{h} \mathrm{m}^{2}$.

\section{Qualitative performances}

The MF membrane performances were controlled by measuring turbidity, COD and color in the feed and in the permeate (Fig. 3). The retention rates were then calculated according to Eq. (1).

It has to be noted that no salt removal by MF was observed; this is due to the reduced size of salt particles toward the important pore size of MF membrane. The turbidity removal exceeds $80 \%$ for all configurations despite for the dyeing effluent which is only of $67 \%$.

The color removal is between 28 and $56 \%$. The best retention value was given by the dyeing bath while $\mathrm{D}+\mathrm{W}+\mathrm{P}$ configuration showed the lowest one. On the other hand, in the case of configurations containing softening bath, relatively high color removal was obtained. This behavior could be in part explained by the color mass balance.

\section{Dye mass balance}

The pressure driven membrane separation can never be performed without mass accumulation (Bacchin et al. 2002). In order to predict the transport phenomena through the MF membrane, an estimation of the dye percentages in the permeate, the concentrate and adsorbed by the membrane were given in Table 4, considering the dye amount in the feed of $100 \%$. When the dyeing effluent was treated alone, about $49 \%$ of initial dyes were found in the concentrate and $17 \%$ was adsorbed by the membrane. Due to the important amount of dye in the concentrate, it can be concluded that an electrostatic repulsion between anionic dyes and membrane charged negatively occurred; this result was in agreement with the study of Porter (1996), who observed that the charge of MF ceramic membrane was responsible for anionic dye rejection. On the other hand, adsorption of dye on the membrane surface also took place, this is often due to the elevated dye concentration in the feed which can cause pore size reduction and contributed to the significant color removal.

$\mathrm{D}+\mathrm{P}$ configuration showed about $53 \%$ of color removal given about $50 \%$ of the mass of dyes in the concentrate. This result can be explained by the increase in repulsion forces established between the dye molecules and the membrane surface due to the anionic surfactant present in the preparation bath. $\mathrm{D}+\mathrm{S}$ configuration also exhibits a color removal of almost $45 \%$ which can be explained by the ability of the cationic surfactant to form voluminous complex called micelle with anionic dye which can be retained by the membrane (Akbas and Kartal 2005).

However, the addition of the washing effluent reduced the color removal of $\mathrm{D}+\mathrm{P}$ configuration and improved it for $\mathrm{D}+\mathrm{S} ; \mathrm{D}+\mathrm{W}+\mathrm{P}$ showed only $28 \%$ of color removal and just $2 \%$ of dye was adsorbed by the membrane, while about $52 \%$ of color retention and $19 \%$ of dye adsorption were obtained with $\mathrm{D}+\mathrm{W}+\mathrm{S}$. This behavior is mostly attributed to the ability of nonionic surfactant present in the washing bath to interact strongly with anionic surfactant (P) and weakly with cationic one (S) (Kartal and Akbas 

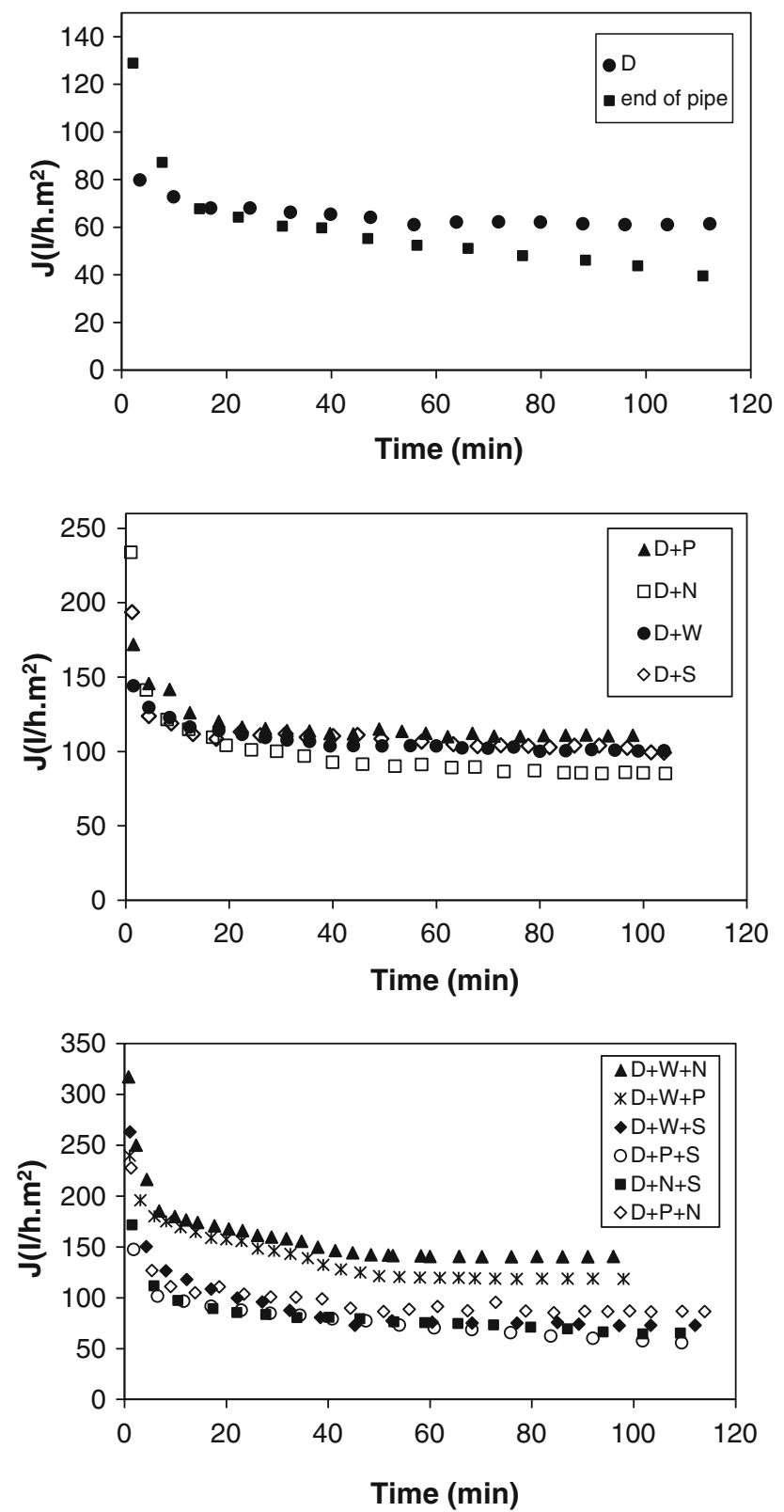

Fig. 2 Variation of the MF permeate flux versus time for different combinations

2005). Thus, anionic and nonionic surfactants interact between each other and not with dye molecules.

Consequently, it was expected that the presence of the softening bath will improve the adsorption behavior of the membrane due to the ability of the cationic surfactant to interact strongly with the reactive dye molecule or with the anionic surfactant. This was proved by the dye mass balance results indicating that the amounts of dye adsorbed by the MF membrane were among the most important values; about $13,19,11$ and $15 \%$, respectively, for $\mathrm{D}+\mathrm{S}$, $\mathrm{D}+\mathrm{W}+\mathrm{S}, \mathrm{D}+\mathrm{P}+\mathrm{S}$ and $\mathrm{D}+\mathrm{N}+\mathrm{S}$ mixed baths.
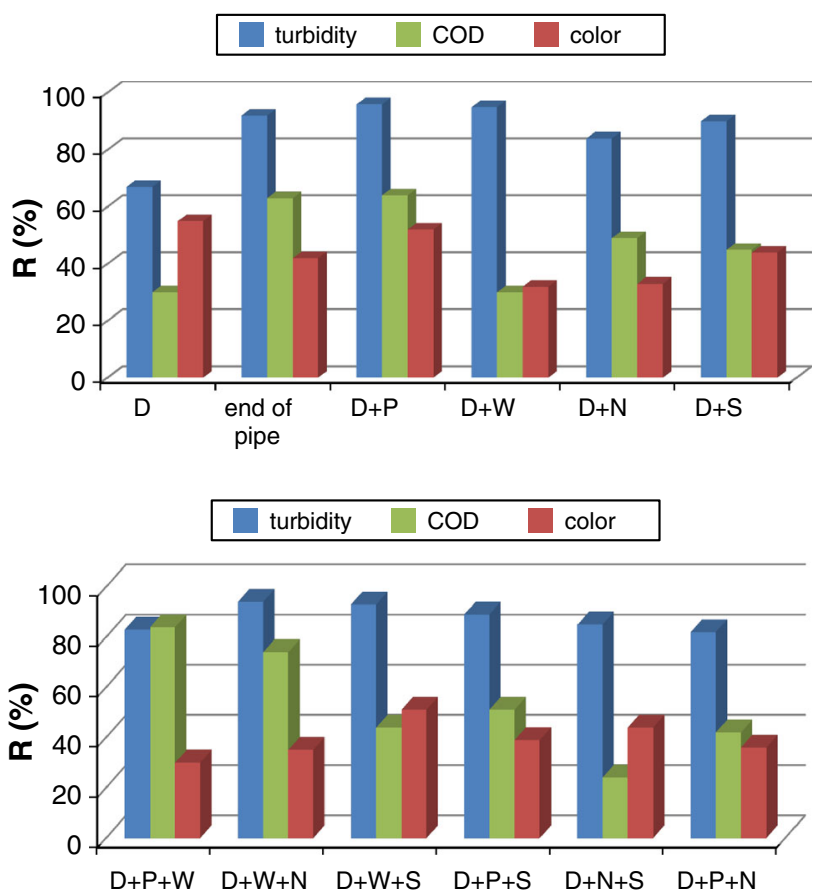

Fig. 3 Turbidity, COD and color removals by MF for different combinations

Table 4 Dye mass balance for MF process

\begin{tabular}{llllllr}
\hline Configuration & $\begin{array}{l}C_{\mathrm{f}} \\
(\mathrm{g} / \mathrm{l})\end{array}$ & $\begin{array}{l}C_{\mathrm{p}} \\
(\mathrm{g} / \mathrm{l})\end{array}$ & $\begin{array}{l}X_{\mathrm{p}} \\
(\%)\end{array}$ & $\begin{array}{l}C_{\mathrm{c}} \\
(\mathrm{g} / \mathrm{l})\end{array}$ & $\begin{array}{l}X_{\mathrm{c}} \\
(\%)\end{array}$ & $\begin{array}{l}X_{\varepsilon} \\
(\%)\end{array}$ \\
\hline $\mathrm{D}$ & 0.76 & 0.34 & 33.60 & 1.48 & 48.68 & 17.72 \\
End of pipe & 0.37 & 0.21 & 43.43 & 0.65 & 43.92 & 12.66 \\
D+P & 0.45 & 0.22 & 36.08 & 0.91 & 50.56 & 13.37 \\
D+W & 0.46 & 0.31 & 50.93 & 0.83 & 45.11 & 3.97 \\
D+N & 0.53 & 0.36 & 50.40 & 0.96 & 45.28 & 4.32 \\
D+S & 0.51 & 0.29 & 41.93 & 0.91 & 44.61 & 13.47 \\
D+W+P & 0.36 & 0.25 & 52.58 & 0.65 & 45.14 & 2.29 \\
D+W+N & 0.34 & 0.22 & 48.68 & 0.62 & 45.59 & 5.74 \\
D+W+S & 0.44 & 0.22 & 36.79 & 0.77 & 43.75 & 19.46 \\
D+P+S & 0.41 & 0.25 & 45.64 & 0.71 & 43.29 & 11.07 \\
D+N+S & 0.54 & 0.30 & 42.08 & 0.92 & 42.59 & 15.33 \\
D+N+P & 0.57 & 0.36 & 47.93 & 1.10 & 48.25 & 3.83 \\
\hline
\end{tabular}

NF step

\section{NF quantitative performances}

In order to investigate the efficiency of the NF treatment, the variation of permeate flux versus time during the filtration tests was determined. Figure 4 shows a typical behavior of NF membrane; the increasing concentration in the vicinity of the membrane surface is an unavoidable phenomenon for pressure driven membrane process which caused the slight decrease in permeate flux with time due to 
cake layer formation (Koyuncu et al. 2004). Besides, the high $\mathrm{pH}$ values of the effluents affected the membrane behavior by reducing the flux due to the increase in dye hydrophobicity under alkaline conditions which causes adsorption of dye molecules on membrane surface (Koyuncu and Topacik 2003).

Unlike MF results, end of pipe effluent gives better performances than dyeing effluent, initial and stabilized permeate fluxes were, respectively, $42-33$ and $31.7-251 / \mathrm{h} \mathrm{m}^{2}$. The best filtration performances were obtained when the dyeing and the preparation effluents were mixed since this last configuration exhibits no significant membrane fouling. In this case, the permeate flux decrease was just about $9 \%$.

\section{NF qualitative performances}

We noticed a total removal of color which was a predicted behavior in agreement with $\mathrm{He}$ et al. (2009) results. Turbidity was also completely rejected, and more than $90 \%$ of COD retention for all configurations after the NF treatment was obtained. The salinity, chlorides and $\mathrm{TH}$ retention rates were calculated according to Eq. (2) and presented in Fig. 5.

Usually, NF is suitable to retain molecules having a size above $1 \mathrm{~nm}$, particularly the soluble molecules and the bivalent ions. However, charge interactions can lead to the rejection of some ions even those smaller than membrane pore size. The DESAL NF membrane is negatively charged at neutral to high $\mathrm{pH}$ (De Vreese and Van der Bruggen 2007). The chloride retention was above $20 \%$ in most configurations, and it reaches $40 \%$ in the dyeing effluent. The observed trends are not in agreement with the chloride molecule size (about $0.25 \mathrm{~nm}$ ), it is to be expected that an electrostatic repulsion was occurred between the membrane and the anions, indicating that chloride removal by the NF membrane was driven by Donnan effect (Peeters et al. 1998; Schaep et al. 1998). The addition of the preparation effluent containing anionic surfactant enhanced the chloride removal to $52 \%$ when the addition of the other baths did not; this behavior is due to the increase in repulsion forces applied between the chloride molecule, the anionic surfactant and the membrane.

Calcium and magnesium amounts are mainly responsible on the total hardness value which is removed for more than $90 \%$ in most cases. This high retention value could be expected as a consequence of the reduced pore size of the NF membrane and its ability to remove bivalent ions.

Reuse of the treated wastewater

\section{Characterization of the treated wastewater}

Since the combined treatment did have neither high salt rejection nor complete COD removal, it was necessary to
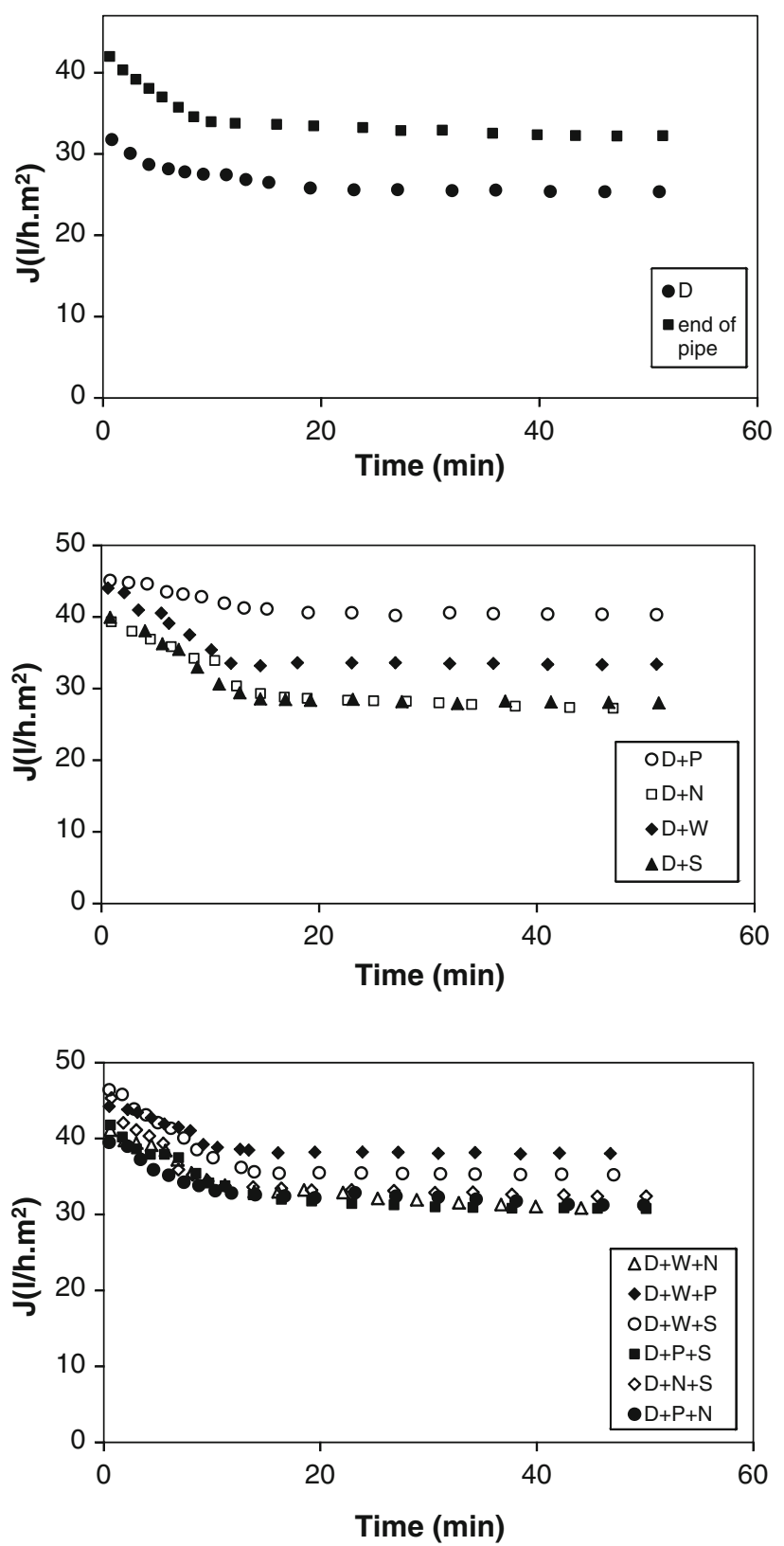

Fig. 4 Variation of the NF permeate flux versus time for different combinations

determine the characterization of released effluents before reuse as well as the stabilized NF fluxes values for each configuration. From Table 5, it can be observed that chlorides and COD concentrations still relatively important especially in the dyeing effluent. Regarding the filtrate quality and the permeate flux values, it seems that $\mathrm{D}+\mathrm{P}$ and $\mathrm{D}+\mathrm{W}+\mathrm{P}$ configurations exhibited the best performances.

Reuse of treated water

Wastewater reuse is advisable not only to reduce the environmental damage of the textile effluent, but also it 

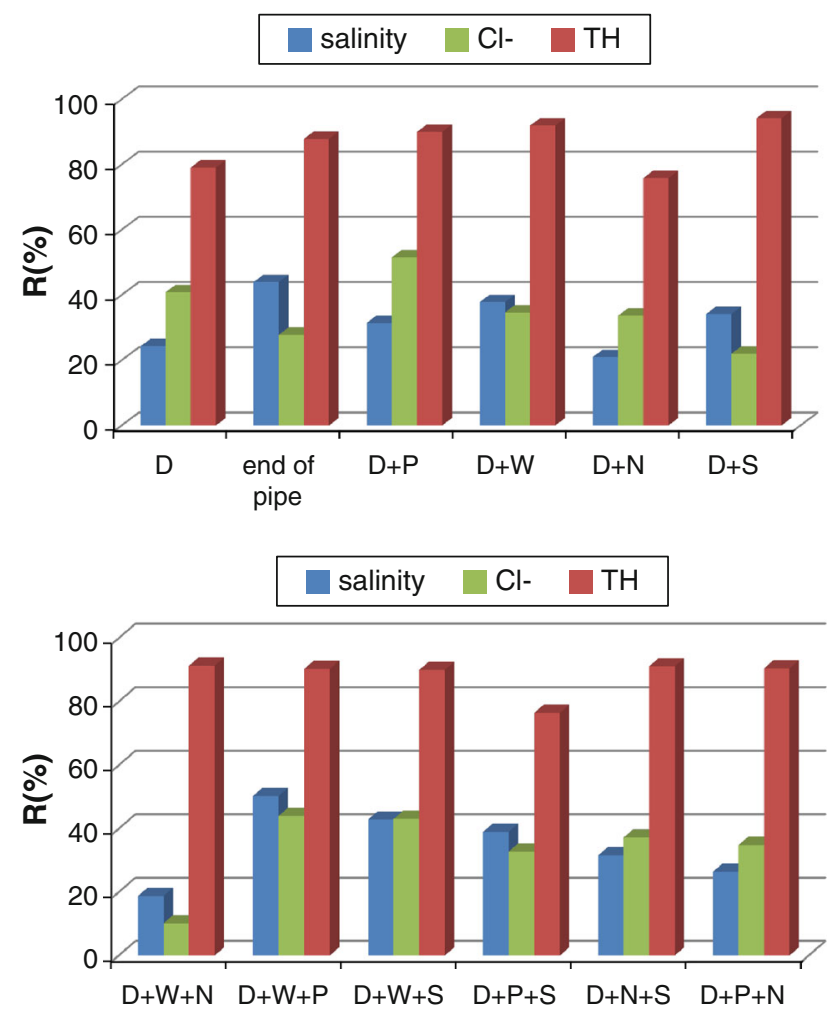

Fig. 5 Comparison of salinity, $T H$ and chlorides removals by NF for different configurations

offers an important economical benefit to the manufacturer since the cost of fresh water increases with the consumption. Experiments showed that the MF/NF system produced about $54 \%$ of the feed effluent as permeate. On the other hand, the industrial data indicated that the cost of process water was about $2.2 \$ / \mathrm{m}^{3}$ including the cost of fresh water and treatment. If the average of daily water consumption of

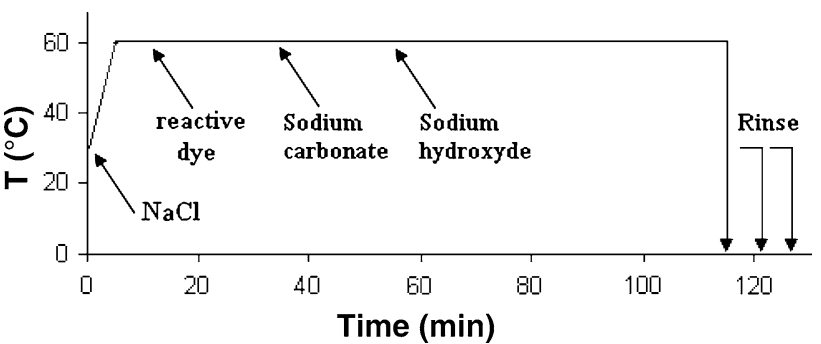

Fig. 6 Dyeing protocol with reactive dye

the factory is $500 \mathrm{~m}^{3} /$ day, the manufacturer can benefit with about $594 \$$ day.

After NF treatment, the treated effluent quality generally satisfied the reuse requirements either in the dyeing bath (Lu et al. 2010) or as washing water (Kurt et al. 2012). In some cases, the NF permeate can also be diluted with fresh water before reuse (Tahri et al. 2012; De Vreese and Van der Bruggen 2007). In the final stage of this work, series of reactive dyeing experiments were done with $100 \%$ of NF permeate in order to study the reusability of the treated water in laboratory scale. A comparative dyeing test was carried out with fresh water. Tests were performed in laboratory dyeing machine using a support of cotton material. As the NF permeate contains again salt, in order to obtain the needed salt concentration in the dyeing bath, the quantity of $\mathrm{NaCl}$ added in the reuse tests corresponds just to the difference between the quantity of $\mathrm{NaCl}$ in the dyeing test with fresh water and in treated water. Figure 6 shows the applied reactive dyeing protocol. Looking to color similarity values (Fig. 7), it can be seen that $\mathrm{D}+\mathrm{S}$, $\mathrm{D}+\mathrm{W}+\mathrm{P}$ and $\mathrm{D}+\mathrm{W}+\mathrm{N}$ led to more than $80 \%$ of similarity. However, $\mathrm{D}+\mathrm{N}$ and $\mathrm{D}+\mathrm{S}+\mathrm{P}$ combinations show no similarity with the standard, while the reuse of the treated D bath shows only $11 \%$ of similarity with the standard.

Table 5 Characterization of the effluents after the combined treatment

\begin{tabular}{|c|c|c|c|c|c|c|c|}
\hline Configuration & $\mathrm{pH}$ & TDS (g/l) & $S(\mathrm{~g} / \mathrm{l})$ & $\mathrm{TH}\left({ }^{\circ} \mathrm{F}\right)$ & $\mathrm{Cl}^{-}(\mathrm{g} / \mathrm{l})$ & $\mathrm{COD}(\mathrm{g} / \mathrm{l})$ & Js $\left(1 / \mathrm{h} \mathrm{m}^{2}\right)$ \\
\hline $\mathrm{D}$ & 9.53 & 88.9 & 81.19 & 46 & 26.25 & 0.267 & 25.85 \\
\hline End of pipe & 8.28 & 13.41 & 10.70 & 17 & 9.06 & 0.136 & 33.95 \\
\hline $\mathrm{D}+\mathrm{P}$ & 8.82 & 17.78 & 14.60 & 12 & 6.88 & 0.098 & 41.26 \\
\hline $\mathrm{D}+\mathrm{W}$ & 8.74 & 25.3 & 22.63 & 21 & 12.99 & 0.124 & 33.54 \\
\hline $\mathrm{D}+\mathrm{N}$ & 7.72 & 28.4 & 28.68 & 58 & 15.55 & 0.091 & 29.33 \\
\hline $\mathrm{D}+\mathrm{S}$ & 8.52 & 26.8 & 22.65 & 10 & 14.71 & 0.023 & 28.56 \\
\hline $\mathrm{D}+\mathrm{W}+\mathrm{P}$ & 8.71 & 17.11 & 16.33 & 18 & 8.29 & 0.031 & 40.22 \\
\hline $\mathrm{D}+\mathrm{W}+\mathrm{N}$ & 8.32 & 11.6 & 9.09 & 10 & 5.17 & 0.028 & 31.57 \\
\hline $\mathrm{D}+\mathrm{W}+\mathrm{S}$ & 8.96 & 15.95 & 13.08 & 18 & 7.28 & 0.219 & 36.54 \\
\hline $\mathrm{D}+\mathrm{P}+\mathrm{S}$ & 8.76 & 13.21 & 10.80 & 59 & 7.16 & 0.125 & 34.15 \\
\hline $\mathrm{D}+\mathrm{N}+\mathrm{S}$ & 8.27 & 16.59 & 14.30 & 22 & 6.69 & 0.086 & 34.39 \\
\hline $\mathrm{D}+\mathrm{N}+\mathrm{P}$ & 8.2 & 17.61 & 15.08 & 16 & 9.25 & 0.108 & 34.12 \\
\hline
\end{tabular}

$\mathrm{J}_{\mathrm{s}}$ stabilized flux 
Fig. 7 Similarity between standard and samples after reactive dyeing tests with $\mathrm{NF}$ permeate

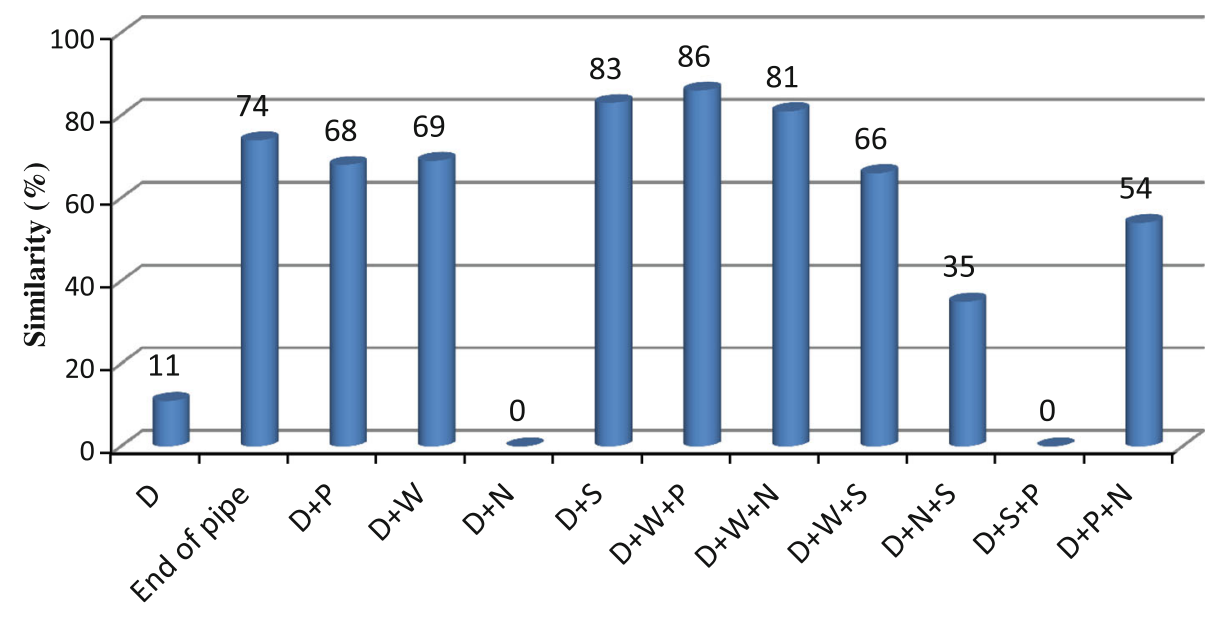

This result can be attributed to the high hardness of the effluent resulting from these mixtures (Table 5). Generally, hard water has an unfavorable effect on dyeing results. Indeed, $\mathrm{Mg}^{2+}$ and $\mathrm{Ca}^{2+}$ ions can react with $\mathrm{RCOO}^{-}$group of the reactive dye which makes the color lighter and discolored patches may also occur.

\section{Conclusion}

A combined treatment using MF and NF processes at pilot scale was investigated for the treatment at source and reuse of real dyeing effluents. The mixing of the dyeing bath with the other effluents from the different baths of the dyeing cycle enhanced in most cases the filtration performances regarding permeate flux and pollutants rejection. Interactions between the components of different baths can have favorable impact on the filtration behavior. Surfactants assume particularly an important role in the dyeing cycle and can be useful for color removal from wastewater. Indeed, while the association of nonionic and cationic surfactant with the dyeing bath gives an enhancement of the dye removal with MF membrane, the coupling of anionic and nonionic surfactants did not. For the different configurations considered in this study, the combined treatment provides almost $100 \%$ of color and turbidity removal, more than $90 \%$ of COD rejection but salt retention did not exceed $50 \%$. Thus, suitable mixture is needed to obtain the best NF performances regarding permeate flux and quality.

Reuse tests were done using NF permeates and following reactive dyeing protocol. Compared to a standard sample using fresh water, the results show that the reusability of the treated water is strongly related to the water hardness. The configuration $\mathrm{D}+\mathrm{W}+\mathrm{P}$ showed the best similarity percentage with the standard $(86 \%)$, the best stabilized NF filtration flux (about $40 \mathrm{l} / \mathrm{h} \mathrm{m}^{2}$ ) and the lowest fouling intensity in the MF treatment (only $2 \%$ of color was adsorbed by the membrane).
Acknowledgment Authors gratefully thank SARTEX Company for their financial and material support of this project.

\section{Nomenclature}

COD Chemical oxygen demand

$\mathrm{C} / \mathrm{F}$ Coagulation/flocculation

MF Microfiltration

NF Nanofiltration

$\mathrm{R} \quad$ Retention

S Salinity

TDS Total dissolved solids

$\mathrm{TH}$ Total hardness

$\Delta \mathrm{P} \quad$ Transmembrane pressure

\section{References}

Akbas H, Kartal C (2005) Spectrophotometric studies of anionic dyecationic surfactant interactions in mixture of cationic and nonionic surfactant. spectrochimica Acta part A 61:961-966

Allègre C, Moulin P, Maisseu M, Charbit F (2006) Treatment and reuse of reactive dyeing effluent. J Membr Sci 269:15-34

Aouni A, Fersi C, Ben Sik Ali M, Dhahbi M (2009) Treatment or textile wastewater by a hybrid electrocoagulation/nanofiltration process. J Hazard Mater 168:868-874

Bacchin P, Si-Hassen D, Starov V, Clifton MJ, Aimar P (2002) A unifying model for concentration polarization, gel-layer formation and particle deposition in cross-flow membrane filtration of colloidal suspensions. Chem Eng Sci 57:77-91

De Vreese I, Van der Bruggen B (2007) Cotton and polyester dyeing using nanofiltered wastewater. Dyes Pigment 74:313-319

Donzé JJ (1988) Colorants textiles. Techniques de l'ingénieur Doc K350:1-6

Ellouze E, Tahri N, Ben Amar R (2012) Enhancement of textile wastewater treatment process using nanofiltration. Desalination 286:16-23

Fersi C, Gzara L, Dhahbi M (2005) Treatment of textile effluents by membrane technologies. Desalination 185:399-409

He Y, Li G-M, Wang H, Jiang Z-W, Zhao J-F, Su H-X, Huang Q-Y (2009) Experimental study on the rejection of salt and dye with cellulose acetate nanofiltration membrane. J Taiwan Inst Chem Eng 40:289-295 
Kartal C, Akbas H (2005) Study on the interaction of anionic dyenonionic surfactant in a mixture of anionic and nonionic surfactants by absorption spectroscopy. Dyes Pigment 65:191-195

Khataee AR, Zarei M, Pourhassan M (2010) Bioremediation of malachite green from contaminated water by three microalgae: neutral network modelling. Clean 38:96-103

Koyuncu I, Topacik D (2003) Effects of operating conditions on the salt rejection of nanofiltration membranes in reactive dye/salt mixtures. Sep Purif Technol 33:283-294

Koyuncu I, Topacik D, Wiesner MR (2004) Factors influencing flux decline during nanofiltration of solutions containing dyes and salts. Water Res 38:432-440

Kurt E, Koseoglu-Imer DY, Dizge N, Chellam S, Koyuncu I (2012) Pilot-scale evaluation of nanofiltration and reverse osmosis for process reuse of segregated textile dyewash wastewater. Desalination 302:24-32

Lu X, Liu L, Liu R, Chen J (2010) Textile wastewater reuse as an alternative water source for dyeing and finishing processes: a case study. Desalination 258:229-232

Majewska-Nowak KM (2010) Application of ceramic membranes for the separation of dye particles. Desalination 254:185-191

Peeters JMM, Boom JP, Mulder MHV, Strathmann H (1998) Retention measurements of nanofiltration membranes with electrolyte solutions. J Membr sci 145:199-209

Porter JJ, Zhuang S (1996) Microfiltration of sodium nitrate and direct red 2 dye using asymmetric titanium dioxide membranes on porous ceramic tubes. J Membr Sci 110:119-132

Ranganathan K, Karunagaran K, Sharma DC (2007) Recycling of wastewaters of textile dyeing industries using advanced treatment technology and cost analysis-case studies. Resour Conserv Recycl 50:306-318

Rierra-Torres M, Bouzan CG, Crespi M (2010) Combination of coagulation-flocculation and nanofiltration techniques for dye removal and water reuse in textile effluents. Desalination 252:53-55

Rozzi A, Antonelli M, Arcarri M (1999) Membrane treatment of secondary textile effluents for direct reuse. Wat Sci Tech 40(45):409-416
Sahinkaya E, Uzal N, Yetis U, Dilek FB (2008) Biological treatment and nanofiltration of denim textile wastewater for reuse. J Hazard Mater 153:1142-1148

Schaep J, Van Der Bruggen B, Vandecasteele C, Wilms D (1998) Influence of ion size and charge in nanofiltration. Sep Purif Technol 14:155-162

Suksaroj C, Héran M, Allègre C, Persin F (2005) Treatment of textile plant effluent by nanofiltration and/or reverse osmosis for water reuse. Desalination 178:333-341

Tahri N, Masmoudi G, Ellouze E, Jrad A, Drogui P, Ben Amar R (2012) Coupling of microfiltration and nanofiltration processes for the treatment at source of dyeing containing effluents. J Clean Prod 33:226-235

Tang C, Chen V (2002) Nanofiltration of textile wastewater for water reuse. Desalination 143:11-20

Unlu M, Yukseler H, Yetis U (2009) Indigo dyeing wastewater reclamation by membrane-based filtration and coagulation processes. Desalination 240:178-185

Uzal N, Yelmaz L, Yetis U (2006) Microfiltration: a pretreatment alternative for indigo dyeing textile wastewater. Desalination 199:515-517

Uzal N, Yelmaz L, Yetis U (2009) Microfiltration/ultrafiltration as pretreatment for reclamation of rinsing water of indigo dyeing. Desalination 240:198-208

Wenzel H, Knudsen HH, Kristensen GH, Hansen J (1996) Reclamation and reuse of process water from reactive dyeing of cotton. Desalination 106:195-203

Zaghbani N, Hafiane A, Dhahbi M (2008) Removal of Safranin T from wastewater using micellar enhanced UF. Desalination 222:348-356

Zahrim AY, Tizaoui C, Hilal N (2011) Coagulation with polymers for nanofiltration pre-treatment of highly concentrated dyes: a review. Desalination 266:1-16 